\title{
REDEEMING THE PROMISE OF OUR LAWS
}

\author{
BRYCE C. TINGLE*
}

In this article. Tingle challenges the claim that reason is the agency by which judges determine the disposition of cases. He engages readers in a deconstruction of both liberal and communitarian rational arguments of the Charter of Rights and Freedoms to demonstrate that the outcome of his deconstructive reading is to render the Charter adjudication impossible as a rational enterprise. Tingle then makes the argument that ethics will permit the reconstitution of reason and the law and that ethics, which he separates from politics, escapes the deconstructive critique.
Dans le présent article. Tingle remet en question l'argument faisant de la raison l'agence par laquelle le juge détermine la conclusion des affaires. L'auteur engage les lecteurs à déconstruire les arguments rationnels de la Charte des droits et libertés, qui relèvent du lihéralisme ou du communautairisme, pour démontrer que la lecture déconstructive rend l'arbitrage de la Charte impossible en tant qu' entreprise rationnelle. Tingle affirme ensuite que l'éthique permetra la reconstitution de la raison et du droit, et que l'éthique, qui est située en dehors de la politique, échappera d̀ la critique déconstructive.

\section{TABLE OF CONTENTS}

I. AN OVERVIEW OF THE ARGUMENT $\ldots \ldots \ldots \ldots \ldots \ldots 1325$

II. WHAT IS AT STAKE: LEGAL REASON $\ldots \ldots \ldots \ldots \ldots \ldots 1326$

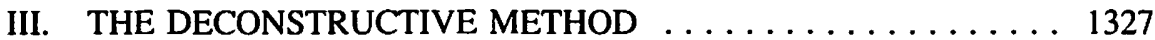

A. THE FIRST SIDE OF THE APORIA:

DECONSTRUCTING THE CHARTER'S

INDIVIDUAL/COMMUNITY HIERARCHY . . . . . . 1330

B. THE SECOND SIDE OF THE APORIA:

DECONSTRUCTING THE CHARTER'S

COMMUNITY/INDIVIDUAL HIERARCHY . . . . . . . . . 1334

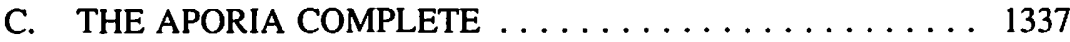

IV. THE TARGET OF DECONSTRUCTION:

REASON AS COERCION .................. 1340

A. DECONSTRUCTION AND PRESENCE . . . . . . . . . 1340

B. DECONSTRUCTING PRESENCE: CAN

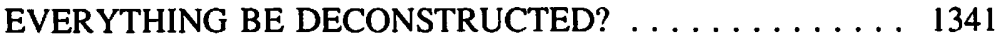

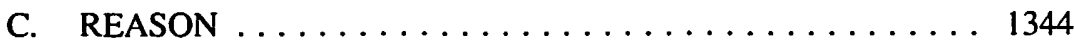

V. THE PROMISE OF THE LAW REVISITED $\ldots \ldots \ldots \ldots \ldots 1346$

VI. LEGAL PRACTICE AFTER

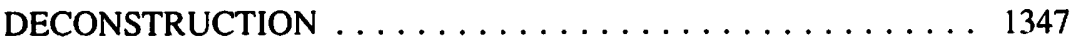

A. DECONSTRUCTION AS A FOUNDATION ........ 1347

B. THE LIMITATIONS OF DECONSTRUCTION

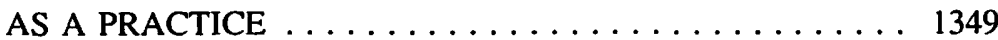

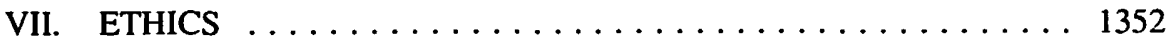

A. REDEEMING ETHICS $\ldots \ldots \ldots \ldots \ldots \ldots \ldots \ldots 1352$

1 would like to thank my father whose life has helped me understand the profoundly ethical nature of the human condition and Jim Falconer for introducing me to the work of Emmanuel Levinas and for his patience and commitment as a teacher. 1 am also grateful to those who read this paper and provided helpful criticisms, in particular Lisa Richardson and Janine Fisher. 
B. REDEEMING REASON ................ 1355

C. REDEEMING THE LAW . . . . . . . . . . . . 1358

VIII. CONCLUSION ....................... 1359

The Law, or at least our usual conception of it, is under attack. The aims and styles of individual critics differ to such an extent that even broadly distinguishing them in terms of their membership in, for instance, the Conference of Critical Legal Studies (cls) or the Feminist movement, obscures as much as it reveals. Despite this, the methods employed by these critics are generally similar. In one form or another, and in varying degrees of self-consciousness, critics of the law employ the techniques and insights of the European Post-Modernists. In particular, though the debt is often not acknowledged, modern legal critics rely on the techniques of deconstruction pioneered by Jacques Derrida and based on the work of Martin Heidegger.'

In general, the deconstruction of the law has not been greeted with joy by judges, lawyers, and other practical legal actors. In the first place, the critics seem to throw the entire enterprise of the law into question, which is a little unsettling to those who practice it in the regular course of their lives. Deconstruction seems to lead the law to the deadends of nihilism, irrationality or inescapable power-relations. In the second place, most of the critiques have been done from various "radical" standpoints with which not all legal actors are comfortable. Both of these fears are misplaced. I shall argue deconstruction is incapable of lending support to any positive political programme, including "radical" ones. I shall also argue that, paradoxically, deconstruction does not lead to nihilism but actually offers the only possibility for the law to administer justice to those brought before it. Deconstruction is a cause not of despair, but of hope, for all those who believe in the promise of our laws.

\section{AN OVERVIEW OF THE ARGUMENT}

Deconstruction presents itself as an alternative logic to that of Anglo-American discourse. Its essential claim, therefore, is that it is radically different from anything most Canadian lawyers will have experienced. For this reason, it may be helpful to preface this paper with an outline of the paper's direction and conclusions.

The law depends on a certain version of rationality characteristic of western culture. In this view, reason is the agency by which judges (first) determine the morally and legally correct principles governing the case and (second) apply these principles to the facts. Deconstruction is a method of showing that any rational argument undercuts itself so that this view of the law is untenable. It is untenable because reason is incapable of

t. The most self-conscious examples of cls and Feminism's reliance on deconstruction are: J.M. Ballan, Deconsiructive Practice and Legal Theory, 96 Yale L.J. 743 (1987); Dalton. An Essay in the Deconstruction of Contract Doctrine, 94 Yale L.J. 997 (1985); M. Kelman. Trashing. 36 Stan. L. Rev. 293 (1984); C. MacKinnon, Feminism, Marxism. Method, and the State: Toward Feminist Jurisprudence, in Critical Legal Studies (A. Hutchinson ed. 1989): D. Williams, Law', Deconstruction and Resistance: The Critical Stances of Derrida and Foucault, 6 Cardozo Arts \& Entertainment 359 (1988). 
either ascertaining the law or applying it neutrally. To illustrate deconstruction's method, the Charter of Rights and Freedoms will be subjected to a fairly simple deconstructive reading. The outcome of this deconstructive reading will be to render Charter adjudication impossible as a rational enterprise.

The claim of legal critics that all legal texts may be deconstructed like the Charter will be evaluated through examining Derrida's deconstruction of time. Once the scope of deconstruction is made visible, the paper will re-examine Western notions of reason to show that nothing escapes the deconstructive critique. Reason is inextricably bound up in a project that deconstruction pronounces as impossible. Several current solutions to this impasse suggested recently by various legal scholars will be examined and ultimately rejected.

Finally, the paper will take a radical turn towards ethics. It will be shown that contrary to the pronouncements of various legal critics, ethics escapes the deconstructive critique. Further, it will be shown that ethics will permit the reconstitution of reason and the law. Finally, it will be shown that the ethical activity of doing justice escapes deconstruction. Only ethics can redeem justice and, therefore, legal practice.

The motives for writing or reading this kind of paper are provided by the promise of the law. The central fact of our experience of the law is that sometimes justice is done and sometimes it is not. This paper is an attempt to take this experience seriously. In a real way the experience of justice and injustice is an experience of the law's promise. Justice may be done, it is possible for it to be done, but it is not inevitable. It never ceases to be only a promise. But it is not any less real for all that.

\section{WHAT IS AT STAKE: LEGAL REASON}

Deconstruction takes as its subject western rationality. It should not be supposed by the title of this section that the law is unique in its standards of rationality. The version of rationality offered below is characteristic of our culture. Science, philosophy, psychology and basket weaving 301, all share in this version of rationality. Despite its pervasive presence, this version of rationality is a relatively recent phenomenon. It is what characterises the time in which we live.

The modern era, ushered in by the Renaissance and Enlightenment, depends on two fundamental assumptions about reason. ${ }^{2}$ The first is that reason is the securing of absolute certainty about a thing. Reason fixes the meaning of a thing down, gives it a place in our intellectual world, and reveals its essential character. The second is that reason is universal: religion, politics, ethics, and justice are all within reason's purview, and are all capable of being made certain. 
In the field of law these assumptions combined to create the modern legal world-view. Roberto Unger identifies two consequences of this view of reason in the law. ${ }^{3}$ The first he calls "objectivism." This is the belief that ethics and justice are amenable to rational "capture" and application. A judge may rationally find "True" ethical or juristic principles and apply them to the cases before him. The need for objectivism results in the creation of a rational system of legal doctrine. The law has the form it possesses (a complex structure of rules, exceptions, principles, and tests) because justice is seen as a rational exercise. Similarly, legal actors see themselves as engaged in a primarily intellectual or knowledge enterprise because they believe that justice is understood through this kind of examination. It is the assurance that the law embodies real elements of justice that provides the moral rationale for the law. If objectivism were impossible, the law would have no moral legitimacy.

The certainty of reason leads to a second aspect of the legal world-view. By using reason, a judge may rationally determine what the law is and then apply it neutrally to the dispute before her. It is reason that allows the judge to become a rule-follower. Judges are not democratically elected, yet they have tremendous power both over those they pass judgment upon and over the law generally. For this arrangement to be morally palatable, it is essential judges do not personally become involved in making decisions. They should simply apply the law given them by elected legislators or history. Unger terms this demand made of reason "formalism".

Deconstruction attacks the pretension of reason to certainty. If reason cannot grant certainty, then the law as a rational statement of justice is finished. The law is only acceptable insofar as it is at least the potential embodiment of justice, and so long as it does not reflect only the personal opinions and prejudices of the judicial elites. Unger correctly identifies the unifying character of modern critiques of the law. Whatever the politics of the critic, modern critiques focus on showing that objectivism and formalism are elusive chimeras. This is usually done through the application of the deconstructive method.

\section{THE DECONSTRUCTIVE METHOD}

The place to begin a discussion of deconstruction is with its method. Properly understood, deconstruction is only a method. It is a method of subverting texts. That is, deconstruction is a way of showing that every argument carries within it the seeds of its own destruction. The wider implications of deconstruction will be discussed below. In general, these implications are not often commented on. This is so for two reasons. First, some critics apparently do not understand deconstruction's implications and attempt to replace the texts they deconstruct with "radical" or "feminist" texts, or with some text based on deconstruction itself. They do not seem to realise that these new texts are also open to deconstructive readings. Second, more sophisticated critics also do not discuss deconstruction's implications, but this is because they recognise that deconstruction is only

R. Unger, The Critical Legal Studies Movemem (1986) at 7. For a historical discussion of the recurring nature of this critique see: W. Walsh, Redefining Radicalism: a Historical Perspective, 59 George Wash. L. Rev. 245 (1991). 
a method, and must remain a method because if it became anything else - for instance, a view of the world - it would in turn be open to deconstruction. This point will be discussed later in the paper. For now, suffice it to say that we will eventually engage in the intellectually incorrect, though not bad faith, enterprise of discussing deconstruction's implications. ${ }^{4}$ We will begin with discussing how it works. This discussion will necessarily be a little superficial.

Stated simply, deconstruction is concerned with hierarchy. That is, it is concerned with hierarchies in thought, not with political or social hierarchies. (Though it has often, wrongly, been understood to have implications for social and political hierarchies). ${ }^{5}$ "Hierarchy" comes from Arche', the Greek word for foundational or essential principles. For the Greeks Arche' imparted sense and direction (telos) to action and to the world. ${ }^{6}$ "Hier-archy" simply refers to division and order in the world of arche'. Some principles are more foundational or primary than others.

Deconstruction suggests these hierarchies in thought occur everywhere, in every argument. J.M. Balkin sets out a tremendously helpful set of examples of these hierarchies of thought. In each of the following hierarchies note that " $\mathrm{A}$ " is "privileged", or elevated above "B".

A is the rule and $B$ is the exception; A is normal and B is abnormal; A is self-supporting and B is parasitic upon it: $A$ is present [to the mind l and $B$ is absent; $A$ is immediately perceived and $B$ is inferred; A is central and B is peripheral; A is true and B is false; A is natural and B is artificial.'

With little effort it is possible to invent further examples of these kinds of hierarchies: A is original and B is secondary; A proceeds and B follows; A is permanent and B is temporary; $\mathrm{A}$ is concrete and $\mathrm{B}$ is abstract; etc.

Deconstruction claims that these hierarchies occur within every argument. To understand why they exist in arguments it is necessary to examine the purpose of arguing. Generally, when we argue, we aim to prove that something is true. That is, we try to show that the side in a dispute we are taking is the right, or most correct, side. In order to do this we choose arguments which will carry authority with the other person. We seek arguments which lead from some foundational point to the conclusion we wish to see vindicated. This attempt to ground an argument in some authoritative starting point is precisely what creates the hierarchies with which deconstruction concerns itself. Every granting of authority to one principle or state of affairs means a reduction of authority to other related positions or states of affairs. In particular, it means a reduction of authority to the opposite of the point privileged.

Supra, note I at 745-6.

Deconstruction may reveal that some of the reasons certain elites are privileged are illegitimate, but Deconstruction is not ever capable of mounting a normative critique against hierarchy. See ibid. at 747.

6. R. Schurmann, Heidegger on Being and Acting: From Principles to Anarchy (1987) at 5. Supra, note 1 at 747. 
For instance, if I were arguing in favour of classical contract doctrine, I might start by grounding my argument in individual freedom. As soon as I do this, however, the role of social pressures and influences in individual behaviour is reduced to an "artificial," "secondary," or "exceptional" role. The role of biological or genetic factors in an individual behaviour is also reduced to "artificial," "sccondary" or "exceptional" status. All three of these hierarchies are taken from the list above. Incidentally, just to show this kind of hierarchical arrangement occurs in every type of argument, these different ways of understanding the role of society and biology in the behaviour of the individual are all represented in a variety of psychological theories: Freudianism, Humanism, and Behaviourism.

Deconstruction's point is that regardless of the subject of the argument, these hierarchies will occur. If here is no hierarchy, there is no argument. This is an important point to remember. Regardless of the style of argument, or the type of foundation or appeal to reality made, it will involve a hierarchy. An argument must start somewhere, and its starting place will exclude, devalue, or reduce, other competing starting points. Try to imagine an argument that does not begin anywhere. Not only would you never be able to start, you would never be able to provide any account of a subject that we could call rational.

The deconstructive method consists of reversing these hierarchies of thought. This reversal is accomplished very simply by showing that the reasons for privileging $A$ would also apply to privileging $B$. So, for instance, if confronted with an argument that $A$ was the rule and $B$ the exception, a deconstructionist would show that B could just as easily be considered the rule, and $A$ the exception. Similarly, shown that $A$ is self-sufficient and $B$ is dependent, a deconstructionist would show that $A$ was dependent on B as well. This is precisely one of the strategies that will be used in deconstucting the Charter of Rights and Freedoms later in the paper.

Before deconstructing the Charter it is necessary to explain a term that is used frequently in the writings of deconstructionists and that will be very important in this paper. "Aporia" is defined in the Oxford English Dictionary with reference to the following example from a 1657 rhetorical handbook:

Aporia is a figure whereby the speaker sheweth that he doubteth, either where to begin for the multitude of malters, or what to do or say in some strange ambiguous thing.

One commentator on the historical role of aporia refers to its "suspect, even sinister, place in the system of traditional rhetoric." Derrida, aporia becomes the closest thing one gets to a cover term for the effects or consequences of deconstruction. Earlier it was suggested that an argument without grounding be imagined. It is impossible to imagine any such argument, yet that is what is left after deconstruction has finished its task. If deconstruction has been successful, the hierarchy of an argument will have been subverted and the speaker will be left with 
nowhere to ground her argument. It will be argued later that this does not leave her speechless, but for now it is necessary to understand that this condition of having all ground cut out from under a position is the situation of aporia.

\section{A. THE FIRST SIDE OF THE APORIA: DECONSTRUCTING THE CHARTER'S INDIVIDUAL/COMMUNITY HIERARCHY}

The frequent complaint in much of the theoretical literature on the Charter is that it is a "liberal" document.' By this it is usually meant that the Charter's role is exclusively to protect the individual's rights and freedoms from the community, defined narrowly as the state. As a liberal text the charter fits into a political tradition that dates at least as far back as John Locke. A dominant theme in this tradition is the guarding of the individual against encroachments made against his fundamental interests by the community. The theoretical literature gives a number of arguments in favour of understanding the Charter "liberally." ${ }^{10}$ These arguments fall into four basic categories.

First, the Charter grants no rights to the community against the individual. Phrased differently, the Charter imposes no duties on individuals towards the community or even other individuals. The focus is not on individual moral responsibility nor is it on a reciprocal relationship between the individual and the group. The individual is primary, in possession of certain rights which are sacrosanct.

Second, the Charter does not grant rights to communities. That is, with the exception of the language and educational provisions, communities do not receive the protection against state interference that individuals receive. Perhaps the best example of this sole concern for the individual may be found in the "right to strike" trilogy of cases. In the most extensively argued result, The Public Service Employees Reference," the plurality of the Supreme Court found that "freedom of assembly" only applied to individuals, it did not apply to labour unions or other groups. Even in their more "communitarian" moments, the plurality used language and concepts that were distinctively individualistic. $^{12}$

Third, the Charter conceives of a political world in which the community is seen primarily as a threat to the individual. There is no indication of a dialectical relationship between the individual and community, nor is there any suggestion in the document itself that the state is an intrinsically good thing. The wording of section one, and the Court's interpretation of it, has been almost always to treat government as a necessary evil. Of

9. See for example: A. Petter, The Politics of the Charter, 8 Sup. Ct. L. R. 473 (1986 and notes 12 \& 13 below.

11. The pun is intentional.

11. Reference Re Public Service Employee Relations Act [1987] I S.C.R. 313.

12. This aspect of the case is brought out in a number of case comments, eg. D. Beatty \& S. Kennelt, Striking Back: Fighting Words, Social Protest and Political Participation in Free and Democratic Societies, 67 Can. Bar Rev. 573 (1989) at 600-1; and A. Petter \& P. Monahan, Developments in Constitutional Law: the 1986-87 Term, 10 Sup. Ct. L.R. 61 (1988) at 96-114. 
course by the time a case reaches section one analysis it has violated an individual right and in this way become an evil. Section one only sorts out if it is a necessary one or not.

Fourth, the Charter assumes a sharp line between the individual and community. This is replicated in a number of ways throughout the jurisprudence. For instance, the individual right is examined first, and an entirely separate examination is conducted later to determine if the right violation is in the interests of a "free and democratic society." Another example might be found in the section 32 of the Charter which applies the Charter only to government not to the actions of individuals. This private/public distinction has been strictly applied by the courts in decisions such as Dolphin Delivery. ${ }^{13}$

The Charter and the jurisprudence arising from it (and there is no point in distinguishing between the two) privilege the individual over the community. The complaints in the academic literature surrounding the Charter all boil down to the concern that the charter has picked up this hierarchy from liberalism. The theorists correctly note that this hierarchy predetermines most decisions, or at least the general direction of Charter jurisprudence. The outcomes of Charter cases inevitably reinforce the liberal status quo. For various reasons the theorists believe there are problems with this status quo. Their solution (being academics, not revolutionaries or even practitioners) is to deconstruct the Charter or a particular case. This deconstruction occurs at various levels of self-awareness. For some they are simply using tools or arguments they have learned from reading other critiques of liberalism. For others, they are aware that their job is to unseat the hierarchy that leaves the individual above the community. What follows is a step-by-step guide to deconstructing anything "liberal" about the Charter.

The first move is to isolate the point where the individual/community hierarchy enters the argument. This entry may not be explicit. While it may not be a straightforward matter, finding the entry point really is not too difficult. There are usually signs. (A reliable one that has received an embarrassing amount of discussion is the public/private distinction.) Somewhere in either the Charter or the court's interpretation of it, the individual will come onto the scene privileged above the community. The privileging may happen a variety of ways. The individual could be seen as existing prior to society, and therefore possessing rights which society, as secondary, has no claim over. The individual can be seen as somehow being more "fundamental" than society; society being merely the aggregate of individuals or their "artificial" creation. The reasons for the privileging are not important. The important thing is to notice where the individual enters the picture. 
Having indicated that the argument relies on the individual/community hierarchy, the next step is to deconstruct this hierarchy by giving reasons for reversing the privileging: placing the community over the individual. There are at least six ways of effectively doing this.

First, the community constitutes the individual at an ontological level. That is, an individual is given her "humanity" by the community. A community gives the individual her language and a sense of time. These are not things the individual invents for herself. The ability to use signs for objects and to separate the future from the past and the present, gives the individual distance from her environment. They make her free. ${ }^{14}$ Without them she would be like an animal.

Since language or a system of interpretations is the way an individual lives her life, in a very real way she is constituted and created by her community. She understands herself, others, and the world in certain unique ways given her by her culture. For instance, she may understand cars and refrigerators in a very different way than a bushman of the Kalahari. An individual's identity is produced by these and other understandings. A woman is at least partially defined by the way she takes the world, so she is truly her culture's creation. Society is implicated in everything a person does, says, and understands; it is implicated in her actually being a "person."

The second argument also deals with the way the community constitutes me, except this is not at as fundamental a level as ontology. Even if an individual's humanity was a result of his own efforts, it is his community that rears him, protects and feeds him while he is young; educates him; allows him a chance to earn a living; gives him technology and accumulations of knowledge; gives him music and stories; gives him possibilities he could not have invented on his own; gives him examples of greatness; gives him human contact, empathy and love; and does a hundred more things for him. The individual owes society a great deal. Particularly in the context of such a socially produced realm as law. For instance, the fact the person can be said to have any rights at all is due to the presence of these socially constructed legal categories of private privilege in the law and society's protection and respect for them. Using any or all of these sorts of arguments, the deconstructionist can emphasise the social aspect of our lives.

Third, the individual is ethically related to the community. The individual/community hierarchy ignores the vital moral obligations we tend to believe the individual owes others in the community. The individual is not morally neutral as the hierarchy assumes. Rather, the individual often understands his highest priorities to be the duties and responsibilities he owes his family, friends, country, and even strangers. This entire side of the moral realm is neglected by the privileging of the individual over the community that occurs in liberalism. Often this privileging results in documents like the Charter which assume ethical obligations only flow one way. But ethics, truly considered,

14. This point is forcefully made in J.J. Rouseau: Discourse on Inequality (1988) at 14-22 and in M. Heidegger, On Time and Being (1969) at 2, 18, etc. 
disrupts and interrupts the purely individualistic life. He is not entirely for himself, but now partly for others. Further increasing the communitarian nature of ethics, these others cannot be separated from the community that shapes them, supports them, or oppresses them. Concern for a victim of sexual harassment must manifest itself partially in working for a change in general attitudes and certain forms of life that oppress or objectify women.

Fourth, communities have an existence outside and separate from the individuals that compose them. This insight might be expressed in a number of different ways. For instance, communities often tend to encourage different kinds of individual behaviour. Everyone has noticed the ways in which individuals change their attitudes, desires and activities according to the different social contexts in which they find themselves. An individual behaves very differently at a church picnic than at a company picnic or at a picnic with her family. This does not just refer to superficial "cocktail party" behaviour. An American is a very different person as an American than if she had been bom in Japan. And a devoutly religious individual would certainly indicate that her life was much different for having participated in a particular religious community. Individuals bear the unmistakable stamp of their cultures and communities.

There are other ways communities have identities separate from the individuals who comprise them. Certain communities have an identity which seems to last through time and transcend the kind of individual behaviour that goes on within the community. A union, for instance, can be characterised as aggressive or passive, and this characterisation can be based on historical behaviour well before most of the current membership entered the union. Similarly, a great deal of attention is spent in business programs on developing certain kinds of corporate culture.

These and other examples show that the usual priority we give individuals in the formation, composition, and creation of certain communities is wrong. The hierarchy runs the wrong way. It is the community that is self-existent, while individuals are merely the agents of a culture.

The fifth strategy is to show how certain values, such as democracy or dialogue, are better represented in societies where the community takes precedence over the individual. Atomistic, apathetic public life in modem liberal societies can be criticised as the inevitable result of our run amok individualism. ${ }^{15}$ In contrast, reinstating concepts such as citizenship ${ }^{16}$ or the value of the community could lead to a more real democracy. Individuals would participate in public affairs and engage again in meaningful dialogue with each other about the future form of the community. People would play a greater role in the creation and maintenance of their society. Differences would be resolved by the people themselves rather than being adjudicated in court or resolved for them by paid public affairs baby-sitters. The values of dialogue and democracy are essentially social or communitarian values.

16. D. Cornell, Toward a Modern/Postmodern Reconstruction of Ethics, 133 Univ. of Penn. L.R. 291 (1985) at $360-378$. 
The sixth and final argument deployed in deconstructing the Charter is an historical argument. This does not, perhaps, have the directly persuasive nature of the previous arguments, but it is useful in shaking the hold the individual/community hierarchy has on the modern mind. The argument consists in pointing out the contingent nature of the hierarchy. The privileging of the individual is a comparatively recent thing. Almost certainly it does not date much beyond Rene Descartes' "modern turn" in philosophy. It really did not receive the character it now possesses until the Enlightenment. The individual self, then, is a comparatively modern achievement. Historically there have been various moments when communities have flourished without modern individualism. Examples usually brought out at this point range from the polis of the Greeks, to the republican vision of the American constitutional Fathers, to the multi-cultural "Toryism" of early Canadian elites. We may be more true to our heritage by seeing the individual in light of the community rather than the other way around.

The results of this deconstruction of the liberal hierarchy are often completely misunderstood. After making arguments of the above kind, a surprising number of critics conclude with the apparent belief that the communitarian vision has been vindicated. ${ }^{17}$ This is usually what gives their critiques of the Charter a decidedly "radical" cast. After bringing the Charter's hierarchy into question they go on to suggest various radical programs that seem to be called for by the importance and centrality of the community in their reconstructed vision of society. And if the critic does not make the consequences of her deconstruction explicit, these consequences are often implied by the average reader. After bringing individual rights into question with arguments like the ones above, it seems that the natural thing to do is eliminate those rights as wrong-headed, or at least radically recast the legal landscape. This is precisely what is not called for by deconstruction.

The end of deconstruction is aporia not Marxism, feminism, or any -ism. Aporia is the situation in which it is impossible to know how to proceed because of the "multitude of matters." It is literally the point at which the presence of two or more competing directions of argument are recognised as both valid or "true," and each hierarchy excludes the other. To illustrate this, it will be necessary to deconstruct the community/individual hierarchy we have seemingly erected in place of the old individual/community hierarchy. Neither the community nor the individual may be privileged and so neither may ground an argument.

\section{B. THE SECOND SIDE OF THE APORIA: DECONSTRUCTING THE CHARTER'S COMMUNITY/INDIVIDUAL HIERARCHY}

In deconstructing the privileged place we have seemingly given the community, we will use the same arguments against the community as we used against the individual. This is important in deconstructive practice for there can be no possibility of giving different

17. The number of critics that do this is potentially infinite. There are three that are fairly representative: A. Petter, Public Wrongs/Private Rights: the Liberal Lie of the Charter, $38 \mathrm{U}$ of Toronto L. J. 278 (1W8); and A. Petter \& D. Monahan, Supreme Court Review 1987, 10 Supreme Court L.R. 61 (1988). For a general overview of this mistake see: R. Bauman. The Communitarian Vision of Critical Legal Studies 46 McGill L.J. 145 (1986). 
sets of arguments different weights and thus resolving the question of whether to ground the argument in community or the individual. Each argument must weigh the same because it appeals to the same kinds of authority.

First there is the ontological argument. While it is true that the individual is constituted by community, it is wrong to say that community constitutes the whole of an individual. We have a very real sense of ourselves as individuals, with an independent and separate existence from the community. If we were not ontologically individual, the old hierarchy and liberalism itself, would not have been persuasive to western society for the last $\mathbf{3 0 0}$ years. What exactly carries a sense of time and uses language but an individual? Ontology is "made flesh" in a particular individual. Further, once equipped with the resources of humanity, individuals are independent ontologically from that which gave them birth. For all that can be said against it, the individual is the most basic ontological block. In Heidegger's terms: it is the place at which Being occurs. The individual is the place where the rubber hits the road; where a community's horizon of understanding is made actual.

Second, we must address the arguments concerning the contributions society makes to the individual. It is difficult to understand what this means except as a very abstract description of the human condition. The individual is given the raw materials by her family and others, but she creates her individual identity and a world for herself out of these raw materials. She is not only capable of using language in unique ways, she is capable of transcending it. That is, as an individual she can break out of the practices and world-views of her culture. It is individuals who own the music, and art, and understandings of their cultures, not the other way around. It is individuals who play and interpret music, who put their own unique understandings and experiences into it. It is individuals who protect and provide for us as children. A man may remember individuals teaching him in school and the individual scientists, philosophers, and writers that he studied. He will not ever remember seeing a community, or being taught by a community, or ever experiencing anything other than, at best, an aggregate of individuals.

In addition, it should not be ignored that the individual must learn or work for everything he gets from others. The individual is responsible for his capacity to enjoy music. He did not inherit it. It took training and a lot of his time. The same is true for the knowledge and education he obtained. These are distinctively individual possessions or attributes. This is not to say that he was not helped by other individuals, it is just that he had to work for them personally as well.

Third, there is the argument of ethics. Beyond everything else, it is in ethics that we experience ourselves as individuals. The moral responsibility for the other that an individual feels is her moral responsibility. By definition it is not a responsibility she can pass on to another. She is riveted to her individuality by an ethical command to her. I cannot share my ethical obligations or give them to another to carry, if I could I would not experience them as ethical obligations. That is what moral responsibility means: I must do something. There is no escaping personal responsibility except to transgress it, and that is not really escaping it. In her ethical life, the individual is Atlas, fixed in place by the weight of her obligations which she carries on her back alone. 
There is another way ethics introduces us into the realm of the individual. It is the concrete situation of an individual that commands us. Indeed we tend to be suspicious of those who talk about their responsibility to "humanity" or the "masses." We see that as a cheap and false morality. It is only since so many people have developed a love for humanity that so many neighbours have gone hungry. The obligation I experience is brought to me by the face and plight of individuals. It is only in discharging my debt by helping individuals, the people before me and in my life, that I am justified. Soldiers report how difficult it is to kill a man whose face you can see, even if he is trying to kill you. In World War II less than half of the American Infantrymen would fire their weapon even when under attack. ${ }^{18}$ It was only when weapons of mass destruction were invented, bombs and artillery, that soldiers were relieved of the terrible moral weight imposed on them by seeing the individuals they were fighting.

The fourth argument had to do with the independent nature of communities. Communities are simply an aggregate of the individuals who make them up. When we say that a community has a particular character we mean that the individuals in that community tend to behave a certain way. Individuals behave differently in different communities because the individuals in different communities expect different things and associate for different reasons. In church groups the individuals come together to share peaceful conversation or meaningful service. In companies individuals come together to make money and get to the top. There is nothing outside of the individuals that determines their behaviour; there are always exceptions in every generalisation about a group. And every individual is free both not to associate with a particular group or to change the way he behaves with that group. It should be kept in mind, as well, that individuals can and do change the communities they live in. This is done by persuading other individuals to change their goals or attitudes. Separating communities from the individuals who make them up seems a little too abstract.

The fifth argument dealt with democratic and dialogical values. A dialogue is a discussion between two individuals. Neither of these individuals are subsumed in the dialogical relationship. Indeed, addressing another person, and being addressed in turn, is an affirmation of one's individuality. In being addressed one is singled out from all others, one enters into a unique relationship with the other person. Further, for dialogues to be real and undistorted, both individuals must be protected from force and coercion, and both should be in relatively equal positions in terms of power, prestige etc. For a dialogue to be valid, great attention must be paid to individual rights. ${ }^{19}$

The same kind of argument may be made about democracy. The individual is not subsumed in the mass. Democracy is the gathering together of individuals, who use compromise and tolerance to advance programs that best represent the interests of a certain number of people, usually the majority. It is run by, and for the benefit of, individuals. Societies which have substituted generalities for the concrete reality of

18. G. Dyer, War (1985) at 101; and E. Levinas, Ethics and Infinity (1982) at 78.

19. The fusion of the individual with the other person in dialogue is described by D. Cornell, Institutionalization of Meaning. Recollective Imagination and the Potential for Transformative Legal Imerpretation, 136 Univ. of Penn. L. Rev. 1135 (1988) at 1178-1196. 
individuals inevitably fall into ugly forms of totalitarianism. ${ }^{20}$ If anything, documents like the Charter remind us of the fact that democracies usually require that certain rights of the individual be off-limits from the majority. Otherwise, not only will members of minority groups run the risk of discrimination and violence. but the very preconditions of democracy will disappear. Individuals need to feel safe and protected if they are to vote free from intimidation.

The sixth argument was a historical attempt to illustrate the contingency of the individual/community hierarchy. But that does not tell the whole story. Drucilla Cornell is correct when she writes: "Liberal subjectivity, however, is not only a part of our modern consciousness but also an important historical accomplishment that should not and cannot simply be negated."21 There are two arguments made by Professor Cornell. First, now that we see ourselves as individuals, separate from the community and occasionally threatened by the community, we cannot go back to losing ourselves in the community. We are what we are, and any program for change that nostalgically looks back to an eldeaic unity, is missing the real weight of history in our lives. Her second argument is that the individual should not be negated. In this she reminds us that one of the ways history is made present in our lives is that it alters the ethical world. The modern development of the liberal individual created real moral claims by individuals against the community. We feel those moral claims as present ethical imperatives. History changes us, for we are our history. That means we are aware of individuals separate from the community and we feel this separation is ethically significant.

At the conclusion of this second deconstructive enterprise, we are left with nothing. That is the point of deconstruction. It is a method of providing an absence. It is not entirely perfect, since after every deconstructive move we seemingly have erected an opposite hierarchy, but this impression may be overcome by reviewing the aporia in its totality.

\section{THE APORIA COMPLETE}

The above deconstructions may have obscured the fundamental hierarchies that were being contested. With the arguments in mind, it is useful to review where we stand now.

First, there was a contest over which entity, the individual or the community, was ontologically more essential or basic. Both are more essential and fundamental than the other. Both provide the ontological basis for the other. The individual human is realised through communities, while communities are realised through individuals. Both are ontologically dependent and independent of the other as well.

Second, there was the question of which was natural and which was artificial. Both the community and the individual are the creation of the other. Both are therefore originary and secondary. 
Third, there was a hidden hierarchy built on which was primary, or preceded the other. Both the individual and the community precede each other. That is, the community exists prior to the individual, but the individual is prior to any community and therefore is not subsumed in it.

There was another question as to which was self-existent, and which was therefore dependent or parasitic on the other. Both, of course, are self-existent and each depends on the other. Without individuals there would be no communities and it is individuals who sustain or alter a particular community's character; yet communities' characters transcend the individuals they contain and modify those individuals' behaviour.

Sixth, there was the problem of ethical primacy. The individual is primary to the community, while the community is primary to the individual. Both are simultaneously primary and secondary. The ethical relation is felt by individuals for individuals, but it represents a break with individual life and the creation of community.

Seventh, there was the question of democracy and dialogue: which social entity is most present, or best represented by these two practices? Both reconciliation and separation are simultaneously present in dialogue and democracy.

Finally, an historical discussion took place in which the individual is both rendered contingent and suspect, and at the same time is rendered essential and ethically significant.

This is the condition of aporia. It is when we discover that any privileged position between the individual and the community is an illusion. The individual depends on the community much like we thought the community depended on the individual. Indeed we have seen that the very reasons that the individual is usually privileged over the community in the Charter would suggest that the community be privileged above the individual. ${ }^{22}$ We should also have the feeling that it is impossible to make the kind of sharp distinction between the individual and the community that the Charter requires. The individual and the community apparently collapse into each other at a variety of points.

With the aporia comes the recognition there is no valid place to ground an argument. The impossibility of maintaining a hierarchy means it is impossible to construct a rational argument as there is no longer a starting place. Imagine being in the position of having to decide a Charter case. Almost every Charter case involves some alleged state encroachment on an individual's rights. Suppose a man refused to pay taxes because the money was being used by the government to fund abortion clinics. Whichever right was pled, a judge would have to argue for or against the man's position. However, there is no rational reason to support either the man or the tax. There is no reason to privilege the community over individual conscience, or to privilege individual conscience over the community. Conscience is a very personal and private matter, but it owes its very existence and the shape it takes to the community. Further, the deconstructive enterprise above indicates there is no real reason to even consider the man separate from the 
community. On the other hand, the deconstructive reading also indicates there is no reason to consider the community as anything more than just an aggregate of individuals and that conscience is a profoundly individual sentiment. The judge is left without rational speech. ${ }^{23}$

This poses certain problems for the law. The law promises justice in the form of conclusions rationally derived from morally acceptable premises. Neither the community nor the individual are morally acceptable starting points. To start reasoning from the individual is to privilege the individual over the community, which is morally indefensible. The community embodies a great many ethical values. To start with the community on the other hand, is to privilege it over the individual. The individual also has moral claims to being recognised and kept separate from society. The law loses its claim to be morally defensible. And, as any rational argument requires this kind of privileging between two morally compelling claims, the law cannot be said to adjudicate between them. In this way the law also loses its claim to do justice. This result of deconstruction is an attack on what Roberto Unger described as "objectivism. ${ }^{124}$ The law can no longer claim that its rational processes produce justice or ethical decisions. Ethics will be violated from the very beginning and justice as an adjudication between competing ethical claims is impossible.

The law not only promises justice, it promises that judges are constrained in their decision making. Judges are not democratically elected. Yet their decisions have an enormous impact on those brought before them, and on society generally. For these reasons we insist judges not pass down judgments composed of their own opinions or ideological beliefs. One of the purposes of legal rationality is to force the judge to bring "the law, not his personal beliefs" to bear on the dispute before him. However, deconstruction reveals there is no reason to choose one rational hierarchy over another. The judge could just as soon choose to begin with the community as with the individual. There is no reason to choose one over the other. This leaves critics of the law with two explanations for the choices the judge does make. Either the decision is the product of an irrational choice, or it is driven by some hidden agenda or ideology. In this latter theory the law's consistent privileging of the individual over the community may best be explained by the law's role in supporting capitalism, patriarchy, or some other hierarchical arrangement. This consequence of deconstruction is an attack on Unger's "formalism."25 The result of the attack is a view of the law as either inherently irrational or the disguised mechanism of power entrenchment and social control.

Together these two consequences seem to suggest the death of law. Indeed Professor Fish wrote a very lucid article with that phrase as its title: the death of law. ${ }^{26}$ Nevertheless it is possible that rumours of law's death have been greatly exaggerated. In

A fairly extreme formulation of this point is found in K. Hegland, Goodbye to Deconstruction, 58 S. Cal. L. Rev. (1985) 1203 at 1211. Hegland argues: "Deconstruction entails a rejection of rationality; indeed, it suggests insanity."

24. R.Unger, The Critical Legal Studies Movemem (1986) at 7.

Ibid.

26. S. Fish, The Death of Law 72 Comell L.R. 1 (1984). 
their eagerness to see modern legal practice collapse in a kind of radical apocalypse, critics may have neglected the possibility they are mistaken as to what has, in fact, died. Deconstruction has ended something, but it may not be the possibility of our legal system doing justice.

If deconstruction is the whole story, justice of any kind is not a possibility. Yet we tend to feel that justice is at least sometimes done in our courts. Following this slender thread of hope to its end will involve a double inquiry. First, we must examine deconstruction more closely and determine what exactly in rationality it makes impossible. Second, we must carefully explore the rationality that deconstruction has made impossible to see if anything may be salvaged.

\section{THE TARGET OF DECONSTRUCTION: REASON AS COERCION}

\section{A. DECONSTRUCTION AND PRESENCE}

Derrida conceives of his major project as exposing the bias in Western reason he calls the "metaphysics of presence."27 This is a difficult phrase to unpack. One way of looking at it is to understand "presence" as what is most "present" to our minds. Derrida is concerned with the tendency in Western rationality to assume that ultimate reality is immediately and transparently present in the mind of an observer or thinker. That is to say, Derrida sees his project as subverting the myth that humans can have unmediated access to reality.

When we think of something we represent it to ourselves. We use different signs to do this act of representation. We may use pictures or words, for instance, to stand for the hedge in our front yard. It is impossible to think of anything without using a sign of one kind or another to represent it. This creates a problem because we recognise that however good our representation, it still will not be the thing itself, it will always fall short. In a dictionary, for instance, we find definitions of things that may be better or worse than other definitions, but they inevitably leave something out. Pictures, paintings, words and all other representations of hedges are also inadequate. They concentrate on some aspects of a thing and leave others unnoticed. On the positive side it may be signs' abbreviation of the things they stand for that make them so useful: so perfect for manipulation in thinking and for giving us distance from the world.

The dream of Western science, philosophy, literary criticism and law has been to get behind the signs somehow and view fundamental, unrepresented reality. That is, Western rationality is an attempt to see the thing-itself. It is not content with the signs we use to represent those things. This is the dream of unmediated presence: of having something present before you just as it is, uninterpreted and unaltered by signs.

This dream of perfect presence is not just manifest in the esoteric work of theorists: it is the most fundamental, common, shared assumption of our culture. Ludwig 
Wittgenstein argued that this belief is contained in the very language we use. According to his account, "Indo-European languages give the appearance of some transcendent thing 'behind' them. When we say a word, we think there is something, the meaning of the word, to which the word points." 28 When we use the word "hedge," we tend to think that in addition to its use in the sentence, the word refers to some independent meaning. Thus our language always points behind it, towards some ultimate "true" meaning of a word.

For the most part, humans go about their lives blurring the distinction between the sign and the thing it represents. In the jargon of the deconstructionists, humans ignore the difference between the "signifier" and the "signified." They forget that when I talk about the hedge I am not granted access to the hedge-itself, I am using a word that possesses certain meanings to myself and my audience.

This is good enough for the average citizen of Western culture, but philosophers never leave good enough alone. It has always been a great scandal in philosophy that we may not have access to ultimate reality. Much of philosophy has consisted of attempts to show some path to experience without signs. This manifests itself in the pursuit of ultimate Truth. Truth 'equals' reality which 'equals' experience of the things themselves, without the distortion of signs. This search for special, ultimate Truth about reality has been the meal ticket for philosophers since Plato. Lawyers have also claimed not only to speak a different language than the average person, but to possess reasoning skills that allow them to discover and apply the law itself. From Austin to Dworkin, lawyers have been placed in the intellectual role of seeking the Truth about the law. It is this search that Derrida attacks as impossible.

This raises an interesting question. Why have philosophers been so anxious to experience the signified itself? And why have Western cultures naturally assumed that they were experiencing this signified? We will have to raise these questions again in the context of our discussion of how reason is supposed to secure certainty. The desire for presence is tied up in the ambitions the West has had for reason throughout its intellectual history.

\section{B. DECONSTRUCTING PRESENCE: CAN EVERYTHING BE DECONSTRUCTED?}

Implicit in Derrida's mission of subverting presence wherever it occurs in our language, is the assumption that presence will always be "subvertable." That is, Derrida seems to claim that presence is impossible. He would never, in fact, say this as it would be itself a claim to presence. However, his more excitable disciples frequently do say things such as there is no such thing as "Truth,"29 and Derrida, himself, shows an unmistakable confidence as he approaches each deconstructive task. On what is this confidence based?

29. S. Fish, Doing What Comes Naturally (1989) at 342. 
Early in his career, Derrida set himself to deconstruct a version of time suggested by Edmund Husserl. Like most philosophers Husserl wanted to show a way humans could experience presence. Husserl called his method "phenomenology" and roughly it consisted of bracketing all our assumptions and opinions about a thing and simply experiencing it. This experiencing of a thing was to be accomplished without any signs in an interior monologue of pure presence:

In a monologue words can perform no function of indicating the existence of mental acts, since indication would be there quite purposeless. For the acts in question are themselves experienced by us at that very moment. ${ }^{30}$

In other words, in our immediate perception of the thing there is no need for signs because we are experiencing the thing itself. We need signs when the thing is not present, as when we are remembering it or speaking about it to another, but when it is immediately before us we have the pure experience of it. In a way this is not such a revolutionary philosophy. It resonates with the certain common-sense notion we have that while I am looking at a thing, the thing-itself is present before me. As you look at this page, your mind has the page-itself, it does not have just a representation of the page. This amounts to saying that as you look at this page you have the whole of the page's reality in your mind, unmediated by corrupting signs.

However, for this attractive picture to be true, the thing must be present before you right now. You must be experiencing it presently. Husserl is right to admit that if the thing is not present, if it is merely remembered, then all we have of it is our mental representations of it. For this reason, Husserl needed to develop a theory of time. This theory of time had to privilege the present, as if the present moment disappeared any chance for presence would disappear as well.

Husserl understood time to be something that was only understood through the "now," or the "living present." We only access the past as it is understood in the present; we only access the future as it is understood in present. Past and future are only horizons of the now. Again this is a fairly common-sense way of viewing time. One only has the past or future as one can imagine them at different "now" moments in one's life. In other words, the present is all one ever has. I think there are even some positive-thinking slogans to that effect.

The actual deconstructive strategy Derrida uses is fairly obscure as it relies on turning two of Husserl's unique categories of experience against Husserl's own project. However, the direction of Derrida's logic is fairly straightforward. First, it is important to remember that we understand things through time. Understanding, looking, seeing, and experiencing reality are all activities. All those words are verbs. They are activities in which things are brought into being. That is, they are activities in which some things are separated out from all the other things in reality and understood by a human. This is a temporal process. Second, it is never a process we have except in other memories of its results. 
We never have the "bringing into being" or the "understanding" of the hedge while this process is going on. We only have the finished product: "Oh look. A hedge!" This should make us think about the nature of the "present." Apparently, we never have the precise "present" we have only the memories, the representations, produced in the present.

There is another way to explain this. For Husserl's theory to work it will not do to have only the signs produced during a succession of 'now' moments, we must have the thing itself as we know it in the present. If we can never experience the present we can never experience the thing itself. But this is the crucial point: the present is a moment we can never know. In the attempt to experience this privileged moment of the now, so that we may know what is this thing before us that we are experiencing, we cannot avoid representing the experience to ourselves. The experience of the moment of presence is "indefinitely postponed, infinitely deferred, perpetually delayed." ${ }^{.31}$ All we ever experience of the present is the representations of the present. The present, itself, we can never know.

Derrida concludes by writing that the present (and presence) is always absent. All we ever have in our minds is the past, the representations already brought into being. By showing the impossibility of ever knowing the present, Derrida shows the impossibility of presence. "The 'present' is what is already past and, therefore, 'presented'."

Derrida's conclusion that presence occurs in a moment that we can never know should help us understand why the Charter was susceptible to a deconstructive reading and why modern critics of the law claim every legal argument is similarly susceptible.

Normally we think that the meaning of a word like "individual" or "community" is regulated by the actual thing it represents. The meaning of the word "individual" is this single person we can point to out in the world. The sign merely represents the reality. But Derrida's deconstruction of time shows that we never have access to this reality. All we ever have is more signs. There is no way to break through language and representations. Where, then, does the meaning of words come from? Derrida's answer is that the meaning of words comes from these other signs. Words function not by pointing behind language, but by functioning within language.

Every word in the language derives its meaning not from a reality that is never experienced, but from its differences and similarities with other words. Take for example the word "individual." Our understanding of this word depends in part on our understanding of the word "community." An individual is defined in part by not being solely considered a member of a community. This is a dialectical relationship: an "individual" is understood partly as not being certain things (a "community", an "animal" etc.). We can never escape the fact that an individual is partly defined by his relationship with what he is not. This is the key to understanding why deconstruction is always possible.

31. Ibid. at 94.

32. D. Comell, Time Deconstruction, and the Challenge to Legal Positivism: The Call for Judicial Responsibility 2 Yale Joumal of Law \& the Humanities 267 (1991) at 278. 
Derrida's arguments about time ultimately make the claim that all we ever have of the world is our understandings of it which are embodied in our representations of it. In the legal world the representations are words or language. We live in and through language. The language we use is our understanding of the world. If the language is always referring to itself, our understanding of the world is always referring to itself. That is, if our language functions through dialectical relationships between words, our understanding of the world will exist in dialectical relationships. Deconstruction shows that in our understanding one concept can never be raised above another concept. In our languagebased understanding of reality, everything depends on other things, so nothing in our understanding is self-existent, original, primary, or foundational. Hierarchies of thought are impossible.

This explanation should do several things. First it should make it clear that any argument, any attempt to privilege a concept, may be deconstructed. Second, it should indicate why deconstruction "works." In our very understanding of a concept is the understanding it cannot stand on its own. In fact, in our very understanding of the concept "individual" there are grounds to privilege the community over it. The dependencies in language create the dependencies in our understanding of reality. Thirdly, it should now be clear why deconstruction is not political. Deconstruction is only a "statement" about language and, therefore, our reality. It cannot give any reason to privilege one thing over another.

\section{REASON}

The scope of deconstruction's critique of the law may only be appraised by considering the nature of reason as understood in Western European cultures. The law is a rational project. It claims its doctrinal structure is rational, and the processes of legal argument and judicial decisions are also rational. To see if anything of the law may escape deconstruction requires an investigation of reason.

Legal actors usually think of reason in terms of a geometric syllogism: ${ }^{33}$ "reason should operate in the step-wise manner exhibited in geometric proofs, and it should have the kind of certainty that geometry has....."34 Reason is defined in relation to this expectation of certainty. Earlier, it was discussed that our language had a tendency to point behind it to some ultimate meaning. Reason's work is to get to that meaning and pin it down. This transcendental meaning is what we consider the Truth of the thing. It is also, of course, presence. Reason is concerned with presence because presence represents certainty. If we experience a thing's presence then we know the whole about that thing. We are certain about its nature and role.

Once reason has obtained the "Truth" of an object it may manipulate that meaning in various ways to arrive at certain conclusions. This is, in fact, what reason consists of: Office, [1970] 2 All E.R. 294 (H.C.). This view is also repeated in R. Aldiss, Legal Reasoning for Lawyers (1983). 
the discovery and manipulation of the ultimate meanings that seems to reside behind our language. Words and other representations are transcended and the thing itself is discussed. Admittedly this discussion must take place in words or other signs, but what is really being discussed is the thing itself. This is the expectation lawyers generally have when they discuss the law. They are actually referring to the law itself, what is really "out there": the will of the legislature.

In keeping with its mission of pinning down meaning so that we may be certain of things, reason fixes things in place and gives them order. One way reason fixes things in place is by bringing us into the presence of the thing-itself that lies behind our signs. Another way reason fixes things in place is by organising things so we may see where they fit in our world. The philosopher Adriaan Peperzak described this process in philosophy; I will frame his comments in the context of the law:

[The Law] thematizes and arranges the world of beings from the perspective of systematic coherence, in which principles, structures, horizons, etc. play the leading part. [Legal] discourse is a most explicit example of such a systemic and foundational language. It gathers beings by asking how they fit into the order of a whole. As the search for foundations, [the law] has a fondness for arche' be they source or germ, end or completion, cause or matter. [Legal] discourse is totalitarian and "archaic." As the gathering of reason, it is "logical" and systematic."

The point of this passage is relatively straightforward. Reason is logical and systematic. It is concerned not just with presence, but with the relationship of presences to each other. In elucidating these relationships, reason uses a number of different devices that should be familiar to us. In the passage quoted above Peperzak indicates that reason classifies things according to whether they are primary or secondary; the beginning or the end; the cause or the effect; a principle or a concrete example. The organisational techniques of reason are the very same hierarchies with which deconstruction concerns itself.

The question might occur, is this necessary? Why does reason need to pin down the meaning of things and organise them into a totality? Reason must do these things if it is to provide certainty. The totality Peperzak describes is the inevitable consequence of the requirement that everything be accounted for and have its place.

What is reasonable is what is "technologically" demonstrable. ... When we demonstrate something is this way, we have removed all possible doubt and laid it before our gaze, finding something that is permanent. unmoving, and unchanging, something we call meaning or the truth." ${ }^{36}$

As soon as certainty is chosen as the goal for reason, the search for presence and system is inevitable. These systems of presence are sometimes called "economies" of presence in the jargon of post-modernism. The word "economy" emphasises not just the connections between presences or the totality created, but also it refers to the abundance 
and lack that constitute the hierarchies. The law is obviously one such economy. The law's doctrinal structure is comprised of various hierarchies (such as "rule and exception," "law and policy," "rights and interests," "private and public," etc.) because the law attempts to rationally organise all legal, moral, and social reality.

Reason's goal of certainty makes sense if it is put into its social context. Reason is a public act. It is intended to overcome the differences individuals have in their beliefs, attitudes, and interests. In order to do this, reason must speak compellingly to all of its objects. The assumption lying behind reason is that a person won't change her mind unless she is forced to. Presence is needed if other people are going to be swayed by one's reasoning. The authority of presence is like a great stick that an individual in an argument can use to force another person to agree with him. Reason is a kind of force that does what all applications of force do: it compels a person against his will. This is obviously the role of reason in legal argument.

It is now possible to see another reason for the hierarchies with which Peperzak and Derrida concern themselves. The hierarchies not only organise things, they also act to grant authority to certain things. In other words they act to privilege certain things. It is the authority conferred by this privileging that convinces people to submit to the logic of the speaker. Because an argument must run from a position of authority to a conclusion, a term in an organisational arrangement is selected, granted superior status, and used as the starting point for the argument.

As law goes about its business organising legal doctrine and convincing judges, lawyers, and litigants of its correctness, it becomes inextricably bound up in the rational project. There is no part of law unaffected by reason's project to secure certainty and grant authority. This appears to mean there is no part of law that escapes the deconstructive practices of its modern critics.

\section{THE PROMISE OF THE LAW REVISITED}

The aim in discussing reason was to see if anything that might be considered "legal" could be salvaged from the critique of presence found in deconstruction. On the contrary, the law appears to be intimately and exclusively concerned with presence. In fact, the law only fills its public role through a coercion of others made possible only by appeals to presence.

This paper began with a deconstruction of the Charter. At the heart of the Charter looms an absence of presence that makes rational adjudication of it impossible. While deconstruction's implications are confined to the actual texts it subverts, Derrida's deconstruction of time provides (at the very least) the confidence that aporia lies in whatever other legal texts we take in hand. These aporias constitute the death of the law. Legal rationality is impossible and so we are left with irrationality and an inevitable abuse of power. It is not so much that law was alive until it was killed by Derrida and his disciples; rather, it is like Frankenstein: it should never have been alive in the first place. 
This would seem to be the end for all hope that the law is a place where justice and ethics may be done. This paper has followed the thread of this promise since the discussion of aporia first threw the future of the law into doubt. I would like to consider the nature of this thread. Its basis was the sentiment possessed by most legal actors that the ethical claims of the parties to a legal dispute are real. Following from this is the feeling that in the court's adjudication of these ethical claims, justice is done or injustice is done, depending on the case. To take the promise of the law seriously is to believe that in at least some cases, it matters how a judge decides the case.

This sentiment of the law's promise is felt more powerfully than the skepticism or nihilism that is seemingly the result of deconstruction. Somehow deconstruction seems curiously unessential to this feeling that it matters how judges decide cases. Whatever the pronouncements of deconstruction, justice and injustice still feels real. As mute testimony to this continuing faith in the promise of the law, most modern critics have not been content with its destruction. Time and time again, some of the law's sharpest critics have attempted to find some reason for believing the law matters. ${ }^{37}$

The purpose for reviewing various attempts to salvage justice from the wreck of the law is two-fold. First, it only makes sense to explore what have already been suggested as plausible reconstructions of the law, in case one of them is viable. Second, the very existence of different projects to salvage the law give strong evidence that deconstruction's critique has missed something. This something is still felt to be valid even after the usual conception of the law is given up.

\section{LEGAL PRACTICE AFTER DECONSTRUCTION}

For modern legal critics, deconstruction is the central fact of their academic lives. It is responsible for radically recasting the intellectual landscape of the law, and its presence on the theoretical scene must be overcome if anything of the law is to survive. It should not be surprising, therefore, that most attempted reconstructions of legal practice place deconstruction at the centre of legal practice. It is either placed as a new foundation for a theory of law, or it is simply engaged in with no apparent object except to convince the uninitiated that current forms of legal practice are hopelessly compromised. It is important to show why deconstruction as a practice is not an attractive stopping point for legal actors. Deconstruction has some real limitations and these must be discussed if the need for law's redemption (not reconstruction) is to be made clear.

\section{A. DECONSTRUCTION AS A FOUNDATION}

While Unger does not use the phrase "deconstruction" (part of his ongoing effort not to use the same language as everyone else), it forms a significant part of his most recent work. ${ }^{38}$ Unger begins his theory of the human personality with our capacity to engage

38. R. Unger, Passion: An Essay in Personality (1982); and the three volumes of R. Unger, Politics: A Work in Constructive Social Theory (1987). 
in deconstruction. This capacity has three consequences for human behaviour. In a thoughtful discussion of Unger's essay Passion, Drucilla Cornell summarises these consequences:

[Human beings possess]...[1] the capacity to break through any particular condition of action; [2] the inability to reach the unconditional situation in which the terms of the activity exclude further insight; and [3] the opportunity to loosen the constraints of conditionality. ${ }^{39}$

Together these activities of humans, or rather possibilities of humans, make them a transcendent animal. Humans are defined by their capacity to transcend the hold a certain view of reality has on their minds and actions. This transcendence is realised through the breaking apart or throwing into radical doubt the signs humans use to create their reality. That is, transcendence is deconstruction.

From this view of the human condition, Unger has gone on to suggest a politics of transcendence. This political arrangement is marked by its extreme plasticity. Institutions are created and destroyed constantly as humans invent new ways of understanding the world and deconstruct the old ways. Institutions are necessary according to Unger, if there is going to be a positive program. However, as institutions inevitably presuppose an understanding of the human condition, they are always false. The human condition is the absence of any particular condition. Adorno describes this as the thesis that "man is open. ${ }^{40}$ For Unger, it is the working out of this openness through the process of deconstruction that politics must reflect.

This brief discussion of Unger's project is important. It is a very sophisticated effort to base a theory of personality and a politics on deconstruction. In showing why it is a project doomed to failure, it will be possible to indicate reasons why deconstruction can never ground any argument. Why, in fact, deconstruction must always remain only a method.

Deconstruction as a method is simply the subverting of hierarchies by turning the reasoning supporting the hierarchy against itself. The reasons for privileging the individual also are reasons for privileging the community. Deconstruction's method, therefore, does not escape participating in reason and its hierarchies. Deconstruction as a method simply substitutes one hierarchy for another. This is why some authors believe that the deconstruction of the privileged position of the individual results in the victory of the communitarian view. As a method, therefore, deconstruction remains enslaved to the metaphysics of presence it has as its target. Unger recognises this in his admission that institutions embodying hierarchies of thought would always exist. The fatal weakness in his theory is the imperative that these hierarchies and institutions be deconstructed. Why should they? 
Deconstruction only seems to transcend the metaphysics of presence insofar as it sets up an aporia. That is, insofar as it points to the absence of presence. ${ }^{41}$ It is not the deconstructive method, itself, but what it gestures towards that constitutes the denial of presence. This denial of presence, this aporia, consists of absence. It is literally nothing. It is the endlessly deferred, the eternally never present. This is not a hopeful starting point for any theory.

Adorno cynically remarks that "the fact we can never tell what man is does not establish a particularly majestic anthropology." ${ }^{42}$ I would argue that it means we can never establish any kind of anthropology. What is needed to provide the foundation of a theory or a politics? Reiner Schurmann sets out the bare minimum that is required of a regulative foundation:

Any ultimate referent that would legitimate human activities would have to subsist, remain constantly present and available, ready to be called upon as a norm wherever action is taking place. ${ }^{43}$

The purpose of a foundation is to give a certain theory authority and legitimation. A foundation's role is to provide direction and rationale for action. It must therefore be present to confer these things whenever it is called upon to do so. It must be constantly present to suggest what action should be taken next.

We have already discussed the aporia in terms of being that which is never present. "In its advent presence withdraws into itself; it is essentially a 'bestowal in withdrawal'." ${ }^{+4}$ We can never know this signifying process. By definition it escapes the signs that constitute our knowledge of the world. It follows that this absence can never be called upon to confer authority or legitimate theory. Aporia is a rupture with all theory. Aporia is silent and so it cannot suggest any activity.

Aporia is anarchy. It is an-arche': the absence of foundation. It is what lies behind deconstruction's destruction of hier-arche'. Any attempt to ground action or theory on it is doomed to failure. This is certainly the case for Unger's project. The "fact" of deconstruction can provide no reason to engage in deconstruction, nor can it provide any direction for deconstruction. In fact, it cannot even be talked about in this way: as if it were a thing. It is not a thing, or a "fact", it is only a method.

\section{B. THE LIMITATIONS OF DECONSTRUCTION AS A PRACTICE}

If Unger's project is hopeless, the intuitions behind it are understandable. By itself, deconstruction is sterile and ethically unsatisfactory. Deconstruction makes all positive programs rationally impossible and is consequently paralysing. Nevertheless, there are hordes of theorists who, for one reason or another (tenure?), do nothing but deconstruct 
various areas of the law. ${ }^{45}$ This has a positive effect on the legal profession's selfawareness, but ultimately leads nowhere. This is so for a number of reasons.

First, deconstruction is a practice without justification or rationale. Derrida's aim may be to subvert presence, but he is usually careful not to suggest why presence is universally susceptible to deconstruction, nor is he able to give any reasons why subverting presence is a useful thing. Justifications of this kind are provided by foundations and these are no longer available. This has certain defects that go beyond the "why" which is left unanswered, and the deconstruction which is left "unmotivated." This will be fleshed out in the points that follow.

Second, deconstruction leads to paralysis. As it consists of the subverting of all rational basis for action, it cannot itself suggest what to do next. ${ }^{46}$ As indicated in the first point, deconstruction cannot even suggest itself as an appropriate activity. This means that the possibility of a positive program is dead. Like Unger's Politics any such program is forever beyond our reach. This is understandably frustrating to the judge faced with the deconstruction of any rational basis of making a decision, who must nevertheless render a decision. Charter cases will not go away, the police and criminals and the innocent will continue to tangle and courts will continue to adjudicate among them, but after deconstruction the judge seems to be left with only arbitrary or irrational grounds for choosing among them. Life is a Monty Python sketch in which the judge vacillates between whether he likes the policeman in his shiny new uniform or the Marlon Brandoesque nonchalance of the accused.

Third, the deconstructive method, insofar as it participates in rational techniques, is riven with tensions the deconstructionist cannot resolve. Of course, the method is undercut by the conclusion it suggests. A far greater problem is that the practice of deconstruction is subverted by its aims. As a practice, the making of rational arguments to subvert hierarchy is not noticeably more sacrosanct than making rational arguments simpliciter. Both, as practices, are in error. It is impossible to be engaged in 'true' deconstructive practice. Any deconstructive practice must deny it is a practice if it is to avoid in turn being deconstructed. But for a deconstructionist to claim she is not engaged in the practice of making of rational arguments is a little like a child claiming that if he holds his hands over his eyes he is invisible.

This leads us directly to the fourth point which is that deconstruction is ultimately sterile. It is ultimately unable to escape the metaphysics of presence it subverts. To use Unger's phrase, it is incapable of transcendence. Deconstruction can say "no" to rationality, but it cannot say "yes" to anything. It remains confined endlessly in a moment of negation. (1987), at 318. The famous American critic concludes his study of the history of American constitutional law with, "Critique is all there is." 
Finally, deconstruction, living in a world comprised only of signs, is unconscious of ethics. This may be seen in three moments. In the first moment deconstruction can work against judicial logic that is serving a moral end. The logic by which a black man is protected from the violence of racists is just as susceptible of deconstruction as the logic that preserves the privileged place of individuals in liberalism. ${ }^{47}$ Furthermore there is nothing within deconstruction itself that is capable of directing it to withhold its work in the presence of justice and morality.

The second moment in which deconstruction is exposed in its blindness to the good has to do with its sterility, discussed above. Society should change for the better. The law should develop, protect interests it has ignored or that have newly arisen. In this process, "one of the things at hand is the abstract, the aspirational, the formal idea of rights." ${ }^{48}$ But it is rights in particular that deconstruction has exposed as empty and indeterminate. The failure of deconstruction to suggest any positive program or give direction for any change in practice makes it useless to those morally engaged with the law. The outcome of deconstruction is not law as politics. The outcome of deconstruction is law as irrational or self-serving.

The third moment of exposure lies in the form of deconstruction's critique. Deconstruction does not make moral criticisms of the hierarchies it subverts. Indeed, a successful deconstruction will render ethics mute by showing that it has nowhere to begin speaking. In the deconstruction that began this paper the individual and the community were given equal ethical weights. Faced with the laws of Nuremburg or the Charter, deconstruction can only reveal that both are illegitimate instances of privileging.

Deconstruction is precisely a practice full of sound and fury signifying nothing. In fact, that is an inelegant way of expressing deconstruction's mission. However, it is unsatisfactory to most of us. It is even unsatisfactory to Derrida ${ }^{49}$ Some deconstructionists have argued that concerns like the ones I raise above are illegitimate. Each of my criticisms seem to start from the position that ethics and positive programs are possible. But that is precisely what deconstruction shows is impossible. No such transcendental perspective exists. This kind of answer has always seemed unsatisfactory to critics of post-modernmism. As one of them writes: such remarks "are uncomfortably similar to 'if you're so smart why do I make more money than you?'." ${ }^{50}$ The feelings of ethics and justice we experience seem too real to be waved away as some kind of false consciousness. This promise that ethics and justice might survive deconstruction is the thread we began following at the start of this paper. It will now be taken up again and followed through the radically other world of ethics.

47. This point is made by an Afro-American scholar, C. West, Reassessing the Critical Legal Studies Movement, 34 Loyola L.R. 267 (1988) at 274.

4.
M. Radin \& F. Michelman, Pragmatist and Poststructualist Critical Legal Practice 139 Univ. of Penn. L.R. 1019 (1991) at 1039.

On this point the best texts are J. Derrida, At This Very Momem in this Text Here I am, in R. Bernasconi \& S. Critchley: Re-Reading Levinas (1991); in the same text there is an essay by $R$. Bernasconi, Skepticism in the Face of Philosophy. Sec also later discussion.

D. Jamieson, The Poverty of Postmodernist Theory 61 Univ. of Colorado L.R. 577 (1991) at 582. 


\section{ETHICS}

Reason is hegemonic. It organises and systematizes the whole of reality, and this would include the moral realm. Like every other realm reason compliments itself in this area on having obtained "true" principles of morality. Plato was insufferably smug about the capacity of philosophy to bring one out from the cave, where most people lived their lives in benighted ignorance, into the presence of the sun, which in his analogy stood for the "good." If ethics, and consequently justice, actually occur only on the level of rationality, then deconstruction destroys any possibility of speaking meaningfully about them. Ethics and justice cannot be a rationally deduced program for action derived from intellectually understood general principles. In other words, ethics and justice cannot be like legal doctrine, traditionally understood, or they will share its fate.

\section{A. REDEEMING ETHICS ${ }^{51}$}

Understood ethically, deconstruction's subversion of reason may look very differently than it did when we treated it from a purely rational standpoint. To highlight the transition I am making from the rational to the ethical realm, I would like to change the vocabulary of deconstruction. "Signifying" will be substituted by "saying." "Sign" will be substituted by "the said." And "the Signified" will be replaced by "the Other." The terms will be used in exactly the same way. The only change is that deconstruction's arid terms are replaced by terms that at least gesture towards the human world in which they are found. For the same purposes I will begin to generally refer to the reason we have been considering as "reason-as-presence." This is to distinguish it from any ethical version of reason we may develop.

All of the moments of aporia revealed through deconstruction have a similar character. They mark the end, or perhaps the falsehood, of reason's power. Regional aporias, such as the one exposed in the Charter only do this for the text in which they reside. The moment of aporia revealed in Derrida's analysis of time is of a different kind. In a way, the aporia of an endlessly deferred present is an 'existential' aporia. For the same reason it gives Derrida confidence that deconstruction is always possible, it gives confidence that rationality as presence will never complete its work. It is this character of the aporia of time that makes it useful to ground a discussion of ethics.

The moment of unmediated exposure to the presence of the thing-itself never comes. Consequently, the moment of saying is forever unknown as well. This never-escaped division of human experience is referred to by post-modernists as the "diachronic" aspect of time. There are four ways the diachronic nature of time protects ethics from the imperialism of reason and the critique of deconstruction.

s. Very little of what follows is original. Nearly all of it may be found in the writings of Emmanuel Levinas. The most comprehensive statement of Levinas' profoundly ethical thought is found in E. Levinas, Otherwise Than Being: Or Beyond Essence (1973). Drucilla Cornell, in her most recent articles, referred to throughout this article, has aslo been very influential in my formulation of these arguments. 
First, ethical acting occurs through time. It is something that literally occurs in the present. We do ethics; it is an activity. In the language of the deconstructionists, ethical acting is a signifying. In the modified language suggested above, ethics is a saying. The saying of ethics occurs in the present. It is literally the coming into being of helpful and kind words or actions. Derrida's deconstruction of time has as its object the lesson that pure saying is a moment we never intellectually experience. It is the moment we never "know". All we ever have of saying is the symbols or representations of it the said. But the said is not ethics, it is just history, an interpretation of what was done. It is not the act itself.

What all this means is that ethical acts, like signifying, escapes reason. Ethical actions can never be captured as presence and turned into a system. Because ethical acts escape reason, they cannot be deconstructed. Human acts are carried out in and through language, but they are not reducible to language. If I use arguments in giving you helpful advice and counsel, though those arguments may be deconstructed, the actual saying of those words cannot. The saying of ethics or the saying of wickedness transcends language and therefore lies completely outside of deconstruction's critique.

The judgment of a court of law is not just a rational argument. The judgment is also the doing of justice or the doing of injustice. The arguments may be deconstructed. The doing of justice, the activity of judging, is never reducible into language and may never be deconstructed. This accounts for why the promise of the law is felt even by its harshest critics. Deconstruction never affected the doing of justice. Though judicial reasoning is never compelling, the judgments are still right or wrong. The compulsion or revulsion we feel on reading a judgment is moral, not rational.

The diachronic nature of time also protects the ethical imperative. This is the second way in which ethics escapes the deconstructive critique. Time places the ethical imperative forever beyond the reach of reason. The ethical imperative is the "I must" or "I should" of personal responsibility. This feeling of obligation exists in time, it is an orientating towards the future. This obligation may not be captured, or seamlessly represented by language, because the obligation is never present. A moral imperative is a constant moral obligation. It is endlessly deferred until it is performed. Once performed, of course, the obligation no longer exists.

There is another way of explaining this. The feeling of ethical obligation is the feeling that one "ought" to do something for someone. It is a sentiment that points beyond itself to the doing of the ethical act. This aspect of moral obligation, this pointing beyond itself, this sense of "ought," this "saying," cannot be captured in the said of that ethical obligation. I can tell you that I must honour my mother and my father, but I cannot put the ethical or imperative aspect of this obligation into words. Because the essence of obligation is a pointing to the future, I can never capture this activity in words and signs. Time, which breaks up our experience of reality, is the essence of ethical obligation. Ethics is the pointing from the unknown past of presencing through the now to the future.

A judge might feel the obligation to consider a woman innocent unless proven guilty. Yet this is not a present obligation. It is the feeling that at some future time the judge 
should presume innocence. This future obligation is what makes the judge's obligation a moral one. If the presumption were simply a rational rule, it could be deconstructed. The presumption would simply be the said of the law. However, every obligation is a saying, it is a pointing beyond itself to its completion. The "activity" of a moral imperative is not capable of being deconstructed. So long as the judge actually feels the saying of moral obligation in the presumption of innocence, any deconstruction of that presumption will seem irrelevant.

The third consequence of time for ethics results from the eternal postponement of presence. Derrida's deconstruction of time reveals the lie that rationality will ever be able to obtain the thing itself. This has significant ethical consequences. Reason illegitimately claims to lead its possessor into the "presence" of another person. This essential meaning of the other person is then seized hold of (Emmanuel Levinas reminds us that "comprehend" is made up of "prehend": to grasp) and appropriated for the rational actor's own purposes. This purpose inevitably involves taking that human being and fitting her into a system, an economy. A human being is converted into an object of thought then pinned down in some larger totality.

By demonstrating that presence is eternally deferred, deconstruction places the "presence" of the Other forever out of reach. The Other is precisely that which is not contained or captured by reason. All reason possesses in its systems and its organisations is the said of the Other. The moment of pure presence of the Other, the saying, is never possible. The Other is protected from the violence of reason, by the humility forced on reason by the moment of aporia.

In the case of the Charter, if the judge possessed absolute Truth about whether a litigant was primarily an individual or part of a community, the judge could take that litigant and place him in a rational scheme. Indeed, the very seizing hold of the litigant as essentially an individual or essentially a member of a community is a stripping of that litigant of his humanity and uniqueness, and a placement of the litigant into some larger, impersonal, rational system. Levinas, a Jew who spent part of the war in a Nazi camp, argues this rational possession is the root of all immorality.

Deconstruction does not make immorality impossible. Murder is a banal fact. It is always possible to rationally capture someone. Deconstruction only shows there is no rational reason for that capture. On reason's own terms, the seizing hold of another person as an "essence" or a "cause" or any other hierarchical/organising term, is a false move. Therefore, the decision to do it is an ethical, not a rational decision.

The fourth and final way time protects ethics is in deconstruction's work with various texts. Reason as it is practised in our culture is morally wrong. Its aim is to force individuals into agreeing with the speaker. Reason's illegitimate appeals to some fundamental reality do not take into account the person spoken to, that person's desires, plans, or problems. Rather these illegitimate appeals to presence are appeals to something external to the listener. As a matter of fact, these appeals to an external legal principle or some other "presence" seem expressly designed so that the speaker does not have to take into account the subjective condition of the listener. No demands except intellectual 
ones are placed on the speaker. He must only be good at bringing the authority of rational hierarchies against those who listen to him. He does not need to be empathetic, understanding, or have any relationship of trust with the person he seeks to compel. His relationship with that person is purely a relationship of power. Rational argument is a matter of dominating a unknown, uncared for, opponent.

Deconstruction attacks the basis on which reason-as-presence is considered coercive. Reason as power depends on a hierarchy rooted in presence. By showing that any rationale for privileging one term of a hierarchy may be used to privilege the other term, deconstruction subverts the hierarchy. In its treatment of time, deconstruction promises that any other appeal to presence is impossible. The result is that no argument can be compelling. There is no external moral or regulative reality "guaranteeing" the validity of an argument. The deconstruction of the Charter that began this paper has as one of its consequences that neither the judge, nor the lawyers, nor the accused is forced to accept the court's reasoning. Any rational argument the judge makes in her decision has, at its base, the privileging of a term that cannot be rationally justified. This preserves the intellectual autonomy and dignity of all brought into contact with the decision. They are all still in charge of determining if they are convinced by the judge's reasoning.

These last two points have brought reason as practised in our culture into question on ethical grounds. Further, deconstruction gives a comprehensive critique of reason on its own, rational, grounds. This creates a significant problem for the law and other public practices. A public practice requires the public exchange of information and points of view. In the past, reason performed this function. If any public discourse like the law is to be preserved, a new conception of something like reason must be attempted. This new shared medium of persuasion must be divorced from illegitimate appeals to presence and from the immoral uses these appeals make possible. This project is driven once again by the promise of the law that judgments do not have to seem arbitrary. There should be reasons for making a legal decision which can be shared and which are persuasive to different people.

\section{B. REDEEMING REASON}

In tracing the possible redemption of reason, I want to look at it from a distinctively ethical perspective. Deconstruction has critiqued reason at its own level of hierarchy and presencing. In contrast I want to examine it in terms of good and evil. By even setting myself on this quest 1 am relying on the above arguments that good and evil do not occur at the level of hierarchy and presencing; otherwise deconstruction would be the end of the story.

Deconstructive readings of various texts consists of the employment of reason against itself. Does this end the possibility of reason? After all, reason is valuable because of its public nature. It is a way of bridging the differences in belief and understanding between people. By eliminating the connection between the sign and the signified, the said and the Other, we are apparently removing the possibility of appeals to some external, objective reality. This would seem to leave us with Nihilism or a vicious relativism. 
We are left with the appearance of nihilism or relativism only because we have used presence to give our statements authority for so long that we have forgotten other possible sources of authority. In the case of the Charter, a judgment can no longer claim its authority from "the law," "the will of the legislature," "the social contract," or any other originary ideal. However, a judgment may still be compelling on ethical grounds. A litigant may be persuaded by the judge's reasoning because it is right, because it seems just. This is not the same kind of compulsion that follows from an appeal to presence. To begin with, ethical claims are legitimate, rational claims are not. But there are other differences that need to be explored.

There is a tradition of reason in our culture that has been neglected for a long time. This tradition of reason, termed "rhetoric," takes the position that reason is merely the persuading of other people. Reasoning involves nothing more nor less than simply trying to get the other person to change her mind. The person changes her mind not because she is compelled to, but because she wants to. She wants to change her mind because she feels it is the right thing to do. The rhetorical tradition of reason replaces the external economies of presence as the regulative ideal, with the listener's beliefs and desires. It is the listener, herself, that regulates rational discourse. Her beliefs, interests and ethical sentiments determine when an argument has been convincing.

James Faulconer gives an ethical definition of "rhetoric:" "a rational account that persuades another without force or deception." 52 This definition requires explanation and discussion. The first element in the definition is the "account" it refer to. An account is a story. Like stories, accounts are given for purposes. A story is told to entertain, or inform, or instruct. Rhetorical accounts are not given solely for their content, the way rational accounts-as-presence are given. Rhetorical accounts are given for the purpose of persuasion. This is not to distinguish purpose from content; the two cannot be sharply distinguished and will, of course, influence each other. Rather, by emphasising the purposes of rhetorical accounts I hope to indicate what regulates them. Reason-aspresence is regulated by the external economies we have described. These economies are external to both speaker and listener. In contrast, rhetorical accounts are regulated by the listener to whom they are offered. They are offered to the other and regulated by ethics. Like a story, a rhetorical account is offered for various purposes which cannot be detached from the needs, beliefs and interests of the listener.

Rational accounts are distinguished from stories in that they have persuasion at their heart. Their purpose is to persuade their listener. Faulconer gives an etymology of the word "persuasion." Persuade is derived from the Latin word persuadeo, which has two roots meaning "movement or change" and "what is made sweet or pleasant." Together the two roots form a word, Persuadeo, which meas "to recommend," "to advocate," "to urge or suggest" and "to advise". These definitions are similar to modern definitions of persuasion. However, it is interesting that each of the meanings in Latin indicates a gesture of friendship. According to its roots, persuadeo means to "move in the direction of what becomes pleasant." The implicit assumption in the word is that something was 
not previously pleasant and has become so through persuasion, the persuasion of a friend or counsellor. .3 $^{3}$

Viewed as a rhetorical practice, reason is an activity, not a noun. Reason is not a thing that may be wielded in an argument to compel a listener to bow to some external presence. Rather, reason is an effort two people make together, finding common ground and exploring it until a conclusion is reached. The necessity of this conclusion is never rational, but ethical. The job of a jugde presiding over a Charter case is to produce reasons for this decision that will persuade the litigants and other readers that justice is being done. This persuasion must begin with the litigants' and readers understanding of justice and ethics and bring them to the judicial conclusion. Therefore, in a judicial act of persuasion it is not the doctrinal legal structure that is central, but the actual human beings who the judge seeks to persuade.

Rhetoric only provides the possibility of a redeemed reason. A speaker may persuade his listener many different ways, some of these are ethical, some are not. It may be useful to consider two immoral forms of persuasion found in the legal world. Indeed, these are both aspects of the usual Western assumptions about reason. The first is persuading another person by an appeal to presence. Ultimately this kind of persuasion is wrong because it is dishonest. Reason as presence can never actually deliver the goods. It is like the emperor's new clothes. People are never actually forced to change their mind by the presence of "the law" or the thing itself, as this is never obtained. People are only persuaded to change their mind. However, the kind of persuasion they are subjected to is immoral because they are persuaded on false and distorted grounds. They think presence has been obtained, and so they submit to a false imperialism. This kind of persuasion is also immoral for all the reasons discussed in the section on ethics: it involves the domestication and coercion of an uncared for opponent.

The second kind of immoral persuasion found in legal argument is a reliance on technique to persuade. This is an attempt to persuade not by appealing to the values and beliefs of the other person, but by making one thing seem like another, or by manipulating the other person. The most extreme examples of this kind of persuasion is provided by advertising and slick political campaigns. It is immoral because it ultimately ignores and does not care for the listener. In most cases it lies to the listener. Western philosophy began in confrontation with this kind of persuasion. Socrates was disturbed by the venality and dishonesty of the Sophists who sold their rhetorical skills to the highest bidder. For them, persuasion was a morally neutral question of technique. Socrates sought to stop the Sophists through involving the regulative power of presence. According to Socrates the mistake of the Sophists was rational; they thought they could argue anything, but really they were bound to the Truth. In contrast, I would argue that the problem with the Sophists is ethical, not rational. They were using other people as a means to wealth and power. 
These two examples of immoral forms of persuasion show that rhetoric is not the equivalent of nihilism or relativism. Ethics, in the form of concern and obligation towards the person one seeks to persuade, is sufficient to regulate rationality. It is not so much that there are positions that cannot be argued because they are false, as there are positions that should not be argued because they are wrong.

\section{REDEEMING THE LAW}

Modern critics of the law claim to have vitiated the law's "objectivist" and "formalist" validity. These claims only make sense if reason is all there is. Both should be revisited in the light of the ethical turn suggested by this paper.

First, deconstruction removed any possibility an argument could be rationally justified. The aporia that lies at the heart of the Charter, for instance, makes beginning with either the community or the individual an irrational, arbitrary, or self-interested choice. In Unger's phrase this destroyed any claim the law might make to an "objective" value. Quite simply, the law does not nor could it ever, represent "what is really out there." Objective reality is never experienced directly - language and signs always intervene.

I should like to reconsider this argument. Legal judgments never really depend for their validity on their faithfulness in reflecting objective legal and social reality. For most people, especially litigants, the validity of a decision depends on whether it is just or not. No one starts a revolution because judges have been insufficiently attentive to precedent or existing legal doctrine. Rather, revolutions begin because the laws have become unjust. The success of our legal system, including the Charter, has nothing to do with its integrity as a rational scheme, but with the justice it produces.

How does justice escape the deconstruction of legal rationality? Justice is a form of ethics, and like ethics, it lies outside of language, signs, and rational argument. Emmanuel Levinas describes the connection between ethics and justice:

The interpersonal relation I establish with the Other, I must also establish with other men; there is thus a necessity to moderate this privilege of the Other, from whence comes justice. Justice, exercised through institutions, which are inevitable, must always be held in check by the initial interpersonal relation. ${ }^{54}$

Justice is done by a court when it adjudicates between competing ethical claims. This is itself an ethical process. ${ }^{55}$

The saying of justice transcends the rational said of justice (which may be deconstructed) in the transcendence of ethics. For instance, the imperatives of justice are

54.

This point is made in N. MacCormick, Reconstruction after Deconstruction: A Response to CLS, 10 Oxford J. of Legal Studies 539 (1990) at 558: "...the value judgments involved in the ordering of legal material include judgments of moral and political value." It is also made though in a very different form throughout D. Cornell, From the Lighthouse: The Promise of Redemption and the Possibility of Legal Interpretation, 11 Cardozo L. Rev. 1687 (1990). 
always a saying. They are always pointing beyond themselves to the thing that should be done. This temporal dimension is uncapturable in language or signs. In a similar way, the actual doing of justice by a court is also a saying, and like any human acting it can never be fully reduced to presence. Justice occurs in the forever unknown present, so it can never be rationally "captured."

The modern critics of the law are wrong in saying the law has no "objective" source of validity. They are right, however, that legal doctrine cannot be that source of validity. This will mean the law will have to change in its self-conception. It can no longer see itself as the development of some rational theme or story. It must see itself primarily as the doing of justice.

The second aspect of the law targeted by its critics is what Unger terms its "formalist" requirements. Deconstruction shows there is no rational necessity behind a judicial decision. At its heart is the irrational and arbitrary choice of which term of a hierarchy will be privileged. Presumably, this choice is made on the basis of the judge's personal political predilections. This does not seem just to the litigants, nor does it seem particularly democratic.

This attack on formalism should also be reevaluated in light of the promise of the law. For most people, again especially for litigants, judgments are compelling or repelling for moral or ethical reasons. One reason this is so is that only lawyers familiar with the area of law and the usually accepted rational hierarchies within it, are capable of saying whether the case is rationally consistent with those hierarchies. Everyone else examines the facts of the case, some of the reasons for the judgment, and the conclusion, and asks whether the decision is just or not. One is tempted to ask that if the decision is unjust, what difference does it make whether it is rationally consistent with the economics of the law. Surely rational consistency, even if it meaningfully existed, is less important than injustice.

The critics of formalism are correct that a decision has a privileging at its heart which is not rationally defensible. They are wrong that this is the equivalent of an arbitrary choice. Justice constrains a judge. Sometimes justice will impel a judge to rule against his interests, or the interests of his class. In fact, justice is usually the only reason most men or women will behave selflessly.

The judge is not left alone and unapproachable in his decisions. The considerations of justice that prompted a decision can be made public. Reason as a rhetorical practice is available to explain the decision and to persuade others to see its merits. The emphasis in a judgment should not be on the rational consistency of its reasoning (which is illusory) but it should be on the doing justice in the case at hand. In a judgment the rational development of the theme of the law should be interrupted by the faces of the parties before it. The court should be seeking to persuade them that the decision was just. To do this it should have to take into account the litigants feelings, attitudes, prejudices, and ethical claims, and try, as a friend, to persuade them its judgment is just. 


\section{CONCLUSION}

It is far beyond the scope of this paper to consider all the consequences of the deconstruction and ethical redemption of the law. At the centre of this paper has been the promise of the law: that justice and injustice are real. Modern legal critics brought the existence or truthfulness of that promise into question, and this paper has sought to defend it. The essence of the promise is ethical, not rational, which is why the term "redeeming the law" seemed more appropriate than "reconstructing the law."

A promise is a future pledge, it is not a present certainty. That is another reason why this paper is about "redeeming" the law. The promise the law has made to generations of practitioners that they might participate in the doing of justice and equity is real. The promise's fulfilment is not inevitable; it can always be betrayed by immoral counsel and insensitive judges. Note that the possibility of justice is contingent on the moral attributes of counsel and the judiciary, not on their knowledge or intellectual attainments. It is precisely the disruption of the world of knowledge and the opening of the world of ethics and justice that deconstruction provides. 